\title{
Small margin excision of periocular basal cell carcinoma: 5 year results
}

\author{
J D Hsuan, R A Harrad, M J Potts, C Collins
}

Br J Ophthalmol 2004;88:358-360. doi: 10.1136/bjo.2003.018531

Background: The traditional surgical management of nodular adnexal basal cell carcinomas (BCC) involves excision with 3-4 $\mathrm{mm}$ margins and primary repair. This may remove a significant area of healthy tissue, often necessitating a complicated reconstruction, without the confirmation that tumour excision is complete.

Methods: Nodular adnexal BCCs were excised with $2 \mathrm{~mm}$ margins, and the repair delayed for 2 days, providing time for histological confirmation of complete excision with formal paraffin sections. Any incompletely excised tumours underwent further resection, which was facilitated by the undisturbed wound edges. Repair was again delayed until further histological examination had confirmed complete excision. Results: 5 year follow up data were available for 55 patients who had undergone small margin BCC excision with delayed repair. 10 patients required more than one excision to achieve clear margins. There were no recurrences.

Conclusion: Small margin excision of nodular adnexal BCCs with delayed repair is a safe and efficient method. Delayed repair allows histological confirmation of complete excision and assists further resection if required. Preservation of healthy tissue is maximised allowing less radical reconstructive surgery without resorting to Mohs' labour intensive technique.

B asal cell carcinoma (BCC) is the commonest periocular malignancy and although metastases are extremely rare, local invasion can cause significant and sometimes severe morbidity. ${ }^{1-3}$ Surgical excision remains the mainstay of treatment, and excellent results are obtained if the tumour is completely removed. ${ }^{4}$ Radiotherapy, cryotherapy, laser ablation, photodynamic therapy, chemotherapy, and immunotherapy have all been described and may be useful for inoperable or widespread disease. ${ }^{5-7}$ Basal cell carcinomas have traditionally been excised with 3-4 mm margins, combined with primary repair. ${ }^{8}$ When the eyelid margin is involved, these excision margins often result in a defect which requires sophisticated reconstructive surgery as direct closure is only possible with the smallest lesions. However, in many patients the excision of BCCs with $4 \mathrm{~mm}$ margins results in the removal of significant amounts of normal tissue. ${ }^{9}$ To achieve the best functional and cosmetic results it is important to minimise the amount of normal tissue loss. ${ }^{10}$ Surprisingly, even 3-4 mm margins are insufficient to guarantee complete excision and in up to $54 \%$ histological clearance is not achieved. ${ }^{11}$ Furthermore, if the wound has been repaired as a primary procedure with an incompletely excised tumour, the surgeon has the onerous task of informing the patient and deciding whether to leave them with known residual tumour or to sacrifice the repair, take further specimens, and then repair the wound again. Mohs' micrographic technique addresses these problems by removing the tumour in multiple steps with histological examination of horizontal frozen sections guiding each subsequent excision, until all margins are tumour free. Not only is complete excision achieved in virtually all cases, but loss of normal tissue is minimised, thereby facilitating reconstruction. ${ }^{12}$ However, Mohs' technique is costly and labour intensive, often requiring numerous excisions and histological examinations. ${ }^{13}{ }^{14}$ Surgeons also require specific training in the technique. We have developed an alternative approach to managing nodular adnexal BCCs, utilising small $2 \mathrm{~mm}$ margins and delayed repair. ${ }^{15}$ This technique preserves healthy tissue, thereby facilitating reconstruction. Delayed repair allows histological confirmation, with formal paraffin sections, of complete removal of the tumour before repair. This study reports the 5 year follow up results of this method.

\section{PATIENTS AND METHODS}

Patients with nodular periocular BCCs presenting to the oculoplastic service at Bristol Eye Hospital from 1994 to 1997 were included in the study. Informed consent was obtained for all patients. Only nodular BCCs were included as they usually have well demarcated clinical margins. Morphoeic, recurrent, and multifocal lesions were excluded as they have ill defined borders and require excision by Mohs' technique, or with wide margins. All lesions were excised under local anaesthesia using lignocaine 2\% with adrenalin 1:200 000 . The excision line was measured and marked $2 \mathrm{~mm}$ from the tumour edge. Standard excision techniques were used with minimal disruption to the edges of the specimen, which was sent for urgent histological examination in formalin. A suture was used to orientate the specimen. After haemostasis, the wound was treated with chloramphenicol ointment and covered with a non-adherent surgical dressing. Repair was delayed for 2-4 days to allow formal paraffin sections to be prepared and examined by the histopathologist. If the tumour was found to extend to any margin of the specimen, a further $2 \mathrm{~mm}$ of tissue was excised from the involved margin and repair delayed until clearance was achieved. The choice of repair was determined by the size and position of the defect, following standard reconstructive techniques.

All wounds were closed except for some medial canthal defects. Those that were less than $1 \mathrm{~cm}$ in diameter and overlying the medial canthal tendon were left to heal by granulation.

\section{RESULTS}

Five year results were available for 55 patients with primary nodular lesions who had undergone excision with $2 \mathrm{~mm}$ margins and delayed repair. The duration of follow up ranged from 5.0 to 8.0 years, average 5.75 years. There were 37 women and 18 men, with an age range of 34-91 years, average 66 years.

Thirty one tumours were on the lower lid, 13 at the medial canthus, six on the upper lid, two at the lateral canthus, and 
one each on the brow, forehead, and cheek. All patients underwent uncomplicated excisions, and none failed to attend for repair. There were no complications in the period between excision and repair, and no patient complained of significant pain. Ten patients had incomplete excisions, all requiring a single further excision of $2 \mathrm{~mm}$ of tissue from the involved margin before histological clearance was obtained. Thus no margin exceeded $4 \mathrm{~mm}$ in total. Reconstructive techniques varied according to the size and position of the defect. They included direct closure with or without lateral cantholysis (19), advancement flaps (11), rotation flaps (four), free skin grafts (nine), free tarsal grafts (two), Hughes tarsoconjunctival flap (six), and leave alone (four). There were no recurrences of the tumour in any patient. Five patients had significant complications. One developed a mild, transient corneal ulcer secondary to a Hughes flap, three had wound dehiscences, only one of which required further suturing, and one patient developed trichiasis.

\section{DISCUSSION}

Basal cell carcinoma is a common condition. The principal aim of any proposed method of management should be complete eradication of the tumour, which will be reflected in a very low recurrence rate. In addition it is important to preserve as much normal tissue as possible, particularly in the periocular region, and thereby allow the best chance of a good reconstructive result with minimal intervention. Ideally the method should also be as simple and cost effective as possible. To our knowledge, this is the first study that reports 5 year follow up data on periocular BCCs of known histological type and stated excision margins.

Traditionally, wide excision margins were adopted in an attempt to ensure total clearance, but this has been shown to be an unreliable method of guaranteeing complete excision. Rakofsky reported incomplete excision in 47 of 95 cases, and of these 11 developed recurrent tumours, giving an overall recurrence rate of nearly $12 \% .{ }^{16}$ Collin reported a recurrence rate of $2.3 \%$ when combining $3-5 \mathrm{~mm}$ margins with histological confirmation of clearance, retrospectively excluding those who had incomplete primary excisions. ${ }^{17}$ If an excision is performed with a primary repair then it is disheartening for the patient and surgeon if the tumour is subsequently found on histology to have been incompletely removed. There have been reports of low recurrence rates following incomplete excision, but this should not undermine the clinician's determination to obtain total clearance, as recurrences may present late with deep involvement resulting in severe morbidity. ${ }^{18}$

While in some patients wide margins may leave residual tumour, in others excessive normal tissue is lost, necessitating complicated reconstructive techniques which might have been avoided. Figure 1 illustrates this with a lower lid nodular BCC with a diameter of $5 \mathrm{~mm} ; 4 \mathrm{~mm}$ margins would result in a defect of $13 \mathrm{~mm}$, approximately half the lid, which would probably require complex transposition or rotation techniques to repair. However if clearance was achieved with $2 \mathrm{~mm}$ margins, the defect would only be $9 \mathrm{~mm}$, and may well close directly, with or without a lateral cantholysis, as illustrated in figures $2-4$.

Mohs' micrographic technique is superior to traditional methods in attaining complete excision while maximising preservation of normal tissue, but it is too expensive and laborious to be used for all periocular BCCs. It should be

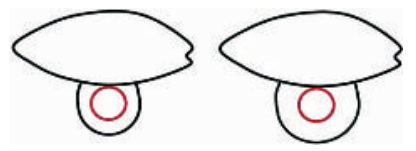

Figure 1 Comparison of traditional $4 \mathrm{~mm}$ excision margins with $2 \mathrm{~mm}$ margins for a $5 \mathrm{~mm}$ diameter BCC.

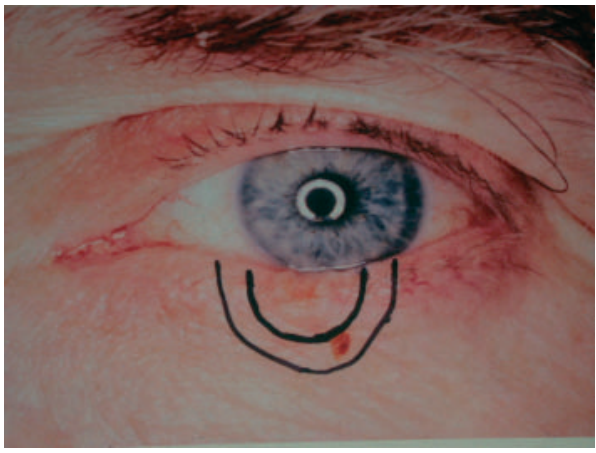

Figure 2 A nodular $B C C$ with $2 \mathrm{~mm}$ and $4 \mathrm{~mm}$ margins marked.

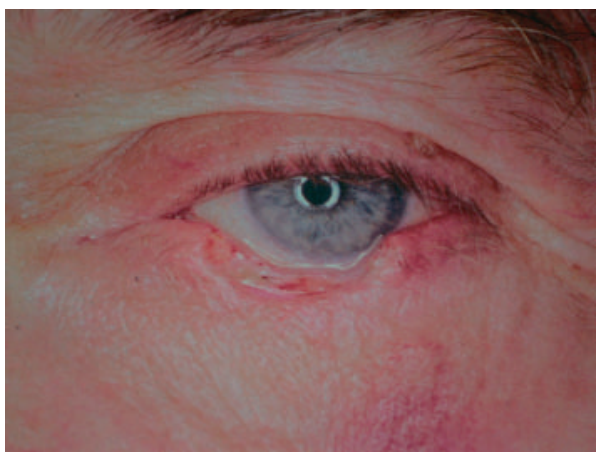

Figure 3 The lesion has been excised with $2 \mathrm{~mm}$ margins.

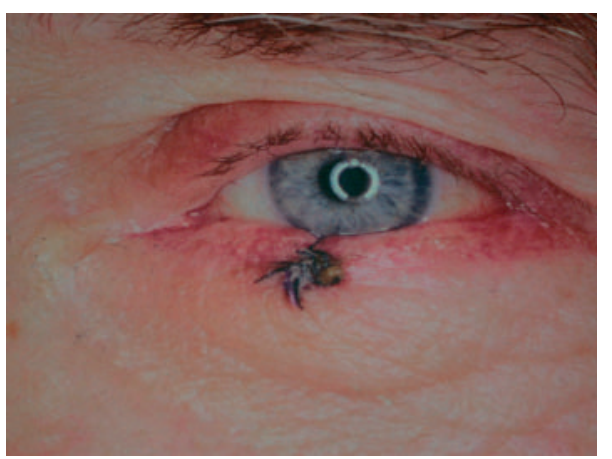

Figure 4 The defect is small enough to be repaired by simple direct closure.

regarded as the gold standard for morphoeic and sclerosing BCCs, as well as other cutaneous malignancies with contiguous spread (not sebaceous cell carcinoma). The method we describe, like Mohs', also has the advantage of histological confirmation of clear margins. It preserves normal tissue nearly as well as Mohs', yet is far less time consuming and can be employed by all ophthalmologists without special training. In addition, if the initial resection shows incomplete excision, further sections can be taken easily as the original wound margins are undisturbed. The main disadvantage of our method is that it involves delayed repair, which requires two theatre sessions and patients having to attend twice. However, we have found that they are usually happy to do this and appreciate the importance of knowing that the tumour has been completely removed. No patient complained of excessive pain or 
disability between excision and repair, and no wounds became infected.

Good cooperation with the histopathology department is a prerequisite but obtaining a report within 36-48 hours should be feasible in most departments. There is a theoretical histological disadvantage of our method which uses vertical bread loaf slices and therefore may miss a minute extension between the examined sections, whereas Mohs' looks at the whole surface. However frozen sections are more open to inaccurate interpretation than formal paraffin sections, and the oblique peripheral sections used in Mohs' do not show the relation of the tumour to the margin as in a vertical section. ${ }^{19}$

The results illustrate the benefits of maximising the preservation of normal tissue with the majority of tumours being repaired by either direct closure with or without a lateral canthotomy, or by a simple advancement flap. These less complex reconstructions generally give superior cosmetic and functional results than large repairs, and are better tolerated by the patient. The complications encountered in our series were attributable to the reconstructive technique, and not a result of the narrow margin excision or delayed repair. If our series of tumours had been managed traditionally with wide $4 \mathrm{~mm}$ margins, a far greater proportion of patients would have required more extensive reconstructive techniques. As it was these were only needed for the very large tumours.

In this series 10 patients required two excisions before complete clearance was obtained. Although the additional surgery is inconvenient, we feel this approach is justifiable on the grounds of preserving normal tissue, and simplifying repairs, for the majority of patients. The only way to reduce the proportion requiring a further excision would be to increase the margin for all patients, which would mean removing further normal tissue in over $80 \%$ of cases. Medial canthal lesions were left to heal by granulation when they fulfilled the criteria described above. The results of this subgroup were good with none experiencing significant postoperative problems.

This technique is well tolerated by patients and requires no special training. This study shows it to be safe with a low recurrence rate at 5 years. The complication rate is also low and reflects the high proportion of patients who were repaired by simple techniques. We suggest that this method is a suitable one for managing adnexal nodular basal cell carcinomas.

\section{Authors' affiliations}

J D Hsuan, R A Harrad, M J Potts, C Collins, Bristol Eye Hospital, Lower Maudlin Street, Bristol BSI 2LX, UK

Correspondence to: Mr R A Harrad, Bristol Eye Hospital, Lower Maudlin Street, Bristol BS1 2LX, UK; r.a.harrad@bristol.ac.uk

Accepted for publication 3 June 2003

\section{REFERENCES}

1 Aurora AL, Blodi FC. Lesions of the eyelid. A clinicopathologic study. Surv Ophthalmol 1970;15:94-104.

2 Urbach F. Incidence of nonmelanoma skin cancer. Dermatol Clin 1991:9:751-5

3 Cook BE, Bartley GB. Epidemiologic characteristics and clinical course of patients with malignant eyelid tumours in an incidence cohort in Olmstead County, Minnesota. Ophthalmology 1999;106:746-50.

4 Doxanas MT, Green WR. Factors in the successful surgical management of basal cell carcinoma for the eyelid. Am J Ophthalmol 1981;91:726-36

5 Margo CE, Waltz K. Basal cell carcinoma of the eyelid and periocular skin. Surv Ophthalmol 1993:38:169-92.

6 Wilson BD, Mang TS, Stoll H, et al. Photodynamic therapy for the treatment of basal cell carcinoma. Arch Dermatol 1992;128:1597-601.

7 Beutner KR, Geisse JK, Helman D, et al. Therapeutic response of basal cell carcinoma to the immune response modifier imiquimod $5 \% \mathrm{cream}$. J Am Acad Dermatol 1999;41:1002-7.

8 Wolf DJ, Zitelli JA. Surgical margins for basal cell carcinoma. Arch Dermatol 1987; 123:340-4

9 Anderson RL. Comment on Glatt HJ, Olsen JJ, Putterman AM. Conventional frozen sections in periocular basal-cell carcinoma: a review of 236 cases. Ophthalmic Surg 1992;23:6-9.

10 Scholda C, Collin JRO. Value of histological clearance of eyelid basal cell carcinomas. Orbit 1990:9:3-5.

11 Chalfin J, Putterman AM. Frozen section control in the surgery of basal cell carcinoma of the eyelid. Am J Ophthalmol 1979;87:802-9.

12 Mohs FE. Micrographic surgery for the microscopically controlled excision of eyelid cancers. Arch Ophthalmol 1986;104:901-9.

13 Downes RN, Walker NPJ, Collin JRO. Micrographic (Mohs') surgery in the management of periocular basal cell epitheliomas. Eye 1990;4:160-8.

14 Callahan MA, Callahan A, Monheit GD. Mohs fresh-tissue technique for periorbital skin cancer. In: Hornblass A, ed. Oculoplastic, orbital and reconstructive surgery, Vol 1: Eyelids. Baltimore: Lippincott, Williams and Wilkins, 1988:643-50.

15 David DB, Gimblett ML, Potts MJ, et al. Small margin (2 mm) excision of peri-ocular basal cell carcinoma with delayed repair. Orbit 1999:18:11-15.

16 Rakofsky SI. The adequacy of the surgical excision of basal cell carcinoma. Ann Ophthalmol 1973;5:596-600.

17 Collin JRO. Basal cell carcinoma in the eyelid region. Br J Ophthalmol 1976;60:806-9.

18 Howard GR, Nerad JA, Carter KD, et al. Clinical characteristics associated with orbital invasion of cutaneous basal cell and squamous cell tumors of the eyelid. Am J Ophthalmol 1992;113:123-33.

19 Rapini RP. Comparison of methods for checking surgical margins. J Am Acad Dermatol 1990;23:288-94. 